\title{
EMA-CO Regimen
}

National Cancer Institute

\section{Source}

National Cancer Institute. EMA-CO Regimen. NCI Thesaurus. Code C67511.

A regimen consisting of etoposide, high-dose methotrexate and dactinomycin

(Actinomycin-D), followed by cyclophosphamide and vincristine, used for the treatment of metastatic gestational trophoblastic tumors (GTT). 